\title{
Paving the Way for Standardized and Comparable Subterranean Biodiversity Studies
}

\author{
David C. CULVER ${ }^{(1, *)}$, Peter TRONTELJ ${ }^{(2)}$, Maja ZAGMAJSTER ${ }^{(2)}$, Tanja PIPAN ${ }^{(3)}$ \\ (1) Department of Environmental Science American University 4400 Massachusetts Ave. NW Washington D.C. 20016 U.S.A.; e- \\ mail: dculver@american.edu \\ (2) Department of Biology University of Ljubljana Večna pot 111 SI - 1000 Ljbuljana Slovenia \\ (3) Karst Research Institute at ZRC SAZU Titov trg 2 SI-6230 Postojna Slovenia \\ * corresponding author
}

\begin{abstract}
A series of potential pitfalls (fallacies) in estimating subterranean biodiversity are outlined: (1) provincialism—-treating different regions differently, especially with respect to new discoveries and undescribed species; (2) equality of described and undescribed species - ignoring the possibility that undescribed species are not really new species; (3) isotropy-assuming all cave regions of similar size have equally rich faunas; (4) scale invariance-ignoring the affect of area on species richness; and (5) misuse of expert opinion - the over-reliance on experts estimates often without comparable estimates for all areas. Some standard procedures are suggested for subterranean biodiversity studies, and the value of such studies is emphasized.
\end{abstract}

Key words: biodiversity, species richness, stygobionts, troglobionts

\section{INTRODUCTION}

The rapid expansion of analytical techniques (e.g., Colwell, Mao and Chang 2004, Colwell 2009) combined with the possibility of both accumulating and incorporating georeferenced data, has had a profound effect on the study of species richness, especially at regional and global scales. The discovery and identification of hotspots, originally defined as areas of concentration of endemic species and that face imminent destruction (Myers 1988), but more broadly used as areas of exceptional species richness has been given special attention, in part because of the growing biodiversity crisis. Typically, such analyses have been done on broad-scale monophyletic groups. For example, bird lists for different localities have a long history.

Analyses of subterranean biodiversity patterns have lagged behind not only because of the difficulty in obtaining large quantities of information on species distributions and site locations, but also because the obligate cave-dwelling fauna is spectacularly polyphyletic, with numerous orders and even classes. Because numerous studies indicate that the cave fauna is strongly convergent (troglomorphic in Christiansen's [1962] formulation), the factors that result in colonization and speciation should also be convergent, or at least that is the working hypothesis of subterranean biodiversity studies.

Culver and Holsinger (1992), using some back of the envelope calculations, suggested that there were upwards of 50,000 obligate cave-dwelling species in the world, including both described and undescribed, discovered and undiscovered species. One of the first, and certainly influential, studies of subterranean biodiversity was that of Sket (1999), who suggested that the Dinaric karst in general and Slovenia in particular was a hotspot of aquatic subterranean biodiversity. Lists of regional faunas (e.g. Peck 1998; Trajano and Bichuette 2009) began to appear, and this activity continues up to the present.

The use of spatially defined localities allowed spatial partitioning of species richness (Malard et al 2009), spatial modeling (Christman and Zagmajster 2012), and analysis of variables that potentially explain subterranean species richness (Dole-Olivier et al 2009a; Martin et al 2009). In addition, important strides have been made in sampling strategy itself (Dole-Olivier et al 2009b; Eberhard et al 2009). All of this activity is for the good because it increases the available information on species richness in subterranean habitats, especially caves.

However, despite these many promising trends, we find that there are some unfortunate trends in both inaccurately estimating the likely numbers of species at different sites, and in mis-interpreting regional and global patterns of subterranean biodiversity. The purpose of this note is not to put forward any claim about continental or global patterns of subterranean biodiversity, but rather it is to point out some fallacies in the literature and to point out some best practices in the analysis of biodiversity patterns. We first point out five fallacies of these analyses, then suggest some best practices, and conclude with some general observations. 


\section{FALLACIES}

The first fallacy is what we have termed the Fallacy of Provincialism. By this we mean treating data from one place differently than data from other places. Typically this takes the form of assuming that only in the 'favored' region under consideration are there undescribed species and species yet to be discovered. For example, Graening, Fenolio and Slay (2012), writing about the fauna of the caves in Oklahoma and Arkansas, a major part of the Ozark Plateau in the central U.S., argue that Culver et al (2003) are incorrect in not including the Ozark Plateau as a hotspot. Culver et al (2003) reported 77 stygobionts and troglobionts for the region, ranking it well below the Interior Low Plateau (Alabama, Tennessee, Kentucky, etc.), Appalachians (West Virginia, Virginia, Tennessee, etc.), and Edwards Aquifer/Balcones Escarpment (Texas) in species richness. Because Graening et al (2012) found 130 stygobionts and troglobionts in the region, they argue that it was incorrect to assume the Ozarks are a low diversity area, as did Culver et al (2003). The fallacy is that they assume no new species have been described outside of the Ozarks since 2003. This is emphatically not the case, as the example from West Virginia discussed next, demonstrates.

The obligate cave fauna of West Virginia provides an instructive example in this regard. Together with Virginia and the Mammoth Cave region of Kentucky, it has been better studied for longer than any other U.S. cave region. Yet the number of described species is still increasing. In 1976, Holsinger, Baroody, and Culver reported a total of 49 described species of obligate cave dwelling species (Table 1). By 2007 Fong et al reported a total of 88 species, and by 2011 , this number had grown to 95 based on new species descriptions by Soto-Adames (2010) and
Shear (2008, 2010). Thus, comparison using 2012 numbers with numbers from other regions based on 2003 data is inappropriate.

Another example is the data on individual cave hotspots. In 2000, Culver and Sket were able to list 20 sites where the combined number of stygobionts and troglobionts was 20 or more. In 2009, 16 additional sites were added to the list (Culver and Pipan 2009). By 2012, Culver and Pipan reported on more extensive data, with10 sites with more than 25 stygobionts and 6 sites with more than 25 troglobionts. This large change is the result of both better record keeping and new discoveries. The taxonomic (Linnean) shortfall and the biogeographic (Wallacean) shortfall is apparently universal in the cave fauna.

The second fallacy is the Fallacy of Equality of Described and Undescribed Species. Because of the Linnean shortfall, which is acute for the subterranean fauna in general in all regions, estimates of species richness, especially for single sites, utilize described and undescribed species. Although their lists were not published, Culver and Sket (2000), in their widely cited paper on hotspots of subterranean biodiversity, relied on both described and undescribed species. This is often a necessity because many, and sometimes most species are undescribed, as is the case with the Brazilian cave fauna (Trajano and Bichuette 2009). The problem is not with listing undescribed species, but in using them in numerical calculations without due caution, and perhaps not giving them the same numerical weight as described species. Undescribed species do not all become described species---some languish, seemingly forever in museum drawers; some are described as new species; and some were incorrectly thought to be undescribed new species but in fact were already described.

The checklists of the troglobiotic and stygobiotic fauna of West Virginia that were published in 1976 by

Table 1 - Number of species known at three time intervals in West Virginia caves.

\begin{tabular}{|c|c|c|c|c|c|c|}
\hline Group & $\mathbf{1 9 7 6}$ species & $\begin{array}{c}\mathbf{1 9 7 6} \\
\text { undescribed. }\end{array}$ & $\mathbf{1 9 7 6}$ total & 2007 species & $\mathbf{2 0 1 1}$ & $\begin{array}{c}\text { Difference--2011 \& } \\
\mathbf{1 9 7 6}\end{array}$ \\
\hline Flatworms & 2 & 2 & 4 & 5 & 5 & 1 \\
\hline Snails & 2 & 4 & 6 & 2 & 3 & -3 \\
\hline Annelida & 0 & 2 & 2 & 2 & 3 & 2 \\
\hline Amphipoda & 7 & 7 & 14 & 16 & 16 & 0 \\
\hline Isopoda & 5 & 2 & 7 & 7 & 7 & 0 \\
\hline Decapoda & 1 & 0 & 1 & 1 & 1 & 2 \\
\hline Millipedes & 6 & 3 & 9 & 7 & 11 & -1 \\
\hline Diplura & 1 & 1 & 2 & 1 & 1 & 9 \\
\hline Collembola & 4 & 2 & 6 & 13 & 15 & 3 \\
\hline Coleoptera & 11 & 3 & 14 & 17 & 17 & 1 \\
\hline Diptera & 0 & 0 & 0 & 1 & 1 & 2 \\
\hline Acari & 1 & 0 & 1 & 3 & 3 & 0 \\
\hline Pseudoscorpionida & 5 & 1 & 6 & 6 & 6 & 2 \\
\hline Araneae & 4 & 0 & 4 & 6 & 6 & 1 \\
\hline Opiliones & 0 & 0 & 0 & 0 & 1 & 20 \\
\hline TOTAL & 49 & 27 & 76 & 87 & 96 & \\
\hline
\end{tabular}


Holsinger et al and again in 2007 by Fong et al, provide an opportunity to track the fate of species that were undescribed in 1976. Holsinger et al listed a total of 27 undescribed species, of which 8 remain unstudied. Of the rest, 13 have been described as new species and 6 turned out not to be new species, but could be assigned to existing species (Table 2). For this one data set, this suggests a "discount rate" for undescribed species of 0.68 $(13 / 19)$. Of course there are unknown and undescribed species, and when these are added, the increase in the number of described species was 47 in 2011 compared to 1976 (Table 1).

This problem is especially acute in regions where there are relatively few described species such as Brazil where Trajano and Bichuette (2009) list more than 125 species $^{1}$ but only 51 are described. Similarly, Guzik et al. (2010) report 407 described obligate cave dwelling species and another 367 undescribed species.

${ }^{1}$ The exact number is impossible to determine because at some entries on their list, they indicate "several" species.
Some mention should be made of the potential impact of different species definitions on species counts. With the growing recognition of the presence of cryptic species (Trontelj et al 2009), the criteria used to delineate these species, such as a rule concerning percent differentiation (Lefébure et al 2006), become critical. A relaxation or the use of alternative criteria, as proposed by Guzik et al (2010) will increase the number of species. They use a combination of unorthodox molecular, phylogenetic and geographic criteria to predict subterranean species in Western Australia. Their procedure might be well suited to identify undescribed species under some species concepts, but at the same time it sheds doubt on their conclusions. This is so because the methodology was not tested against any existing and thus comparable taxonomic array, and because it is likely to produce higher estimates than more traditional approaches used on other continents. These considerations are important mostly at the level of regional, or gamma diversity comparisons. Single cave, or alpha diversity is typically less affected by differences in taxonomic practice, although cases of morphologically cryptic species living together

Table 2 - List of species from West Virginia, listed as undescribed new species by Holsinger et al (1976). Current status from Fong et al (2007), Shear (2008, 2011) and Soto-Adames (2010).

\begin{tabular}{|c|c|c|c|}
\hline Species & Location & Current Status & Change \\
\hline Sphalloplana & Harper & S. culveri & new species \\
\hline Phagocata & Harper & P. angusta & new species \\
\hline Fontigens 1 & $\begin{array}{c}\text { Bazzle, Harman, Marthas, } \\
\text { Piddling Pit }\end{array}$ & F. tartarea & old species \\
\hline Fontigens 2 & The Hole, McClung & F. tartarea & old species \\
\hline Fontigens 3 & Hunt & unstudied & unstudied \\
\hline Lartetia & McClung & F. turritella & new species \\
\hline Stylodrilus & Ct. Street, Tub & S. beattei & new species* \\
\hline Trichodrilus & Tub & T. culveri & new species* \\
\hline Apocrangonyx 1 & Arbuckle, Parlor, Haynes, Snedegar & Stygobromus pollostus & new species \\
\hline Apocrangonyx 2 & $\begin{array}{l}\text { Piddling Pit } \\
\end{array}$ & Stygobromus nanus & new species \\
\hline Stygobromus 1 & Ditmer & S. biggersi & new species \\
\hline Stygobromus 2 & Coburn & S. spinatus & old species \\
\hline Stygobromus 3 & Patton & S. redactus & new species \\
\hline Stygonectes 1 & Dyers & $\begin{array}{l}\text { S. allegheniensis or } \\
\text { S. morrisoni }\end{array}$ & old species \\
\hline Stygonectes 2 & Stillhouse & S. culveri & new species \\
\hline Caecidotea & Beacon & unstudied & unstudied \\
\hline Caucasonethes & Indian & unstudied & unstudied \\
\hline Pseudotremia 1 & Hunt & Zygonopus weyeriensis & old species \\
\hline Pseudotremia 2 & Devils Kitchen & unstudied & unstudied \\
\hline Pseudotremia 3 & Organ & Zygonopus weyeriensis & old species \\
\hline Plusiocampa & Dyepot & unstudied & unstudied \\
\hline Pseudosinella & Neely Farm & P. testa & new species \\
\hline Sinella & Mill Run plus many & S. agna & new species \\
\hline Pseudanophthalmus 1 & Mercer Co. & unstudied & unstudied \\
\hline Pseudanophthalmus 2 & Bowden & unstudied & unstudied \\
\hline Pseudanophthalmus 3 & Patton & unstudied & unstudied \\
\hline Kleptochthonius & Organ & K. hetricki & new species \\
\hline$*_{\text {in }}$ press before pub. & & & \\
\hline
\end{tabular}


in a single cave have been reported (e.g., Cobolli Sbordoni et al 1990; Zakšek et al 2009).

Parenthetically we note that there is no discernible difference in species delineation criteria employed by European and American taxonomists. Culver et al (2006) showed difference in species per genus ratios between the two continents, although there is a difference in description of subspecies, which American taxonomists rarely do.

The third fallacy is the Fallacy of Isotropy. A simple method to estimate unknown species richness is to use known species counts for a small, well studied area, and then multiply up, using the number of such small areas to cover a region. For example, in their estimate of global species richness of troglobionts and stygobionts on a global scale, Culver and Holsinger (1992) began with an estimate of the number of stygobiotic amphipod species, both described and undescribed (see the Fallacy of Equality of Described and Undescribed Species), then used ratios of different groups in Botosaneanu's (1986) Stygofauna Mundi, estimate the actual proportion of non-amphipods, and multiply up from there. The problem with this approach is that it is unlikely that the number of amphipod species in the Virginias is representative of the number of amphipod species elsewhere, at least in the U.S. This is especially so because one of the reasons this amphipod fauna was well known was that it was diverse and interesting.

Starting with an especially rich component of the fauna can lead to overestimates, and even absurd results. In her comprehensive study of the copepods of epikarst drips in six Slovenian caves, Pipan (2005) found up to ten species of copepods in one single drip (see Pipan and Culver 2007a). Since populations of epikarst copepods typically have ranges of maximum linear extent on the order of magnitude of 100m (Pipan and Culver 2007b), one might estimate 350 species of epikarst copepods from 35 drips included in Pipan's (2005) study. This absurd result, where the best drip is used to multiply up, is strikingly different from the 37 species actually known in the region.

Yet another example can be taken from Zagmajster et al 's (2008) study of the remarkable troglobiotic beetle fauna of the northwest Balkans, with nearly 300 described species. If we took the most species rich $400 \mathrm{~km}^{2}$ quadrat, with 21 species, and multiplied it by the number of quadrats (263), we would obtain the incredible estimate of 5523 troglogiotic beetle species in the region! The errors in this hypothetical example are (1) using the best quadrat and (2) the very process of multiplying up, with the expectation of the same number of beetle species in all quadrats. Zagmajster et al (2008) estimated species richness (including described, undescribed, and unknown species) was about 730 species for the entire region, based on the highest estimate of various species richness estimators. In addition, Zagmajster et al (2010) provide a way of estimating species richness in a gridded area, essentially by estimating missing diversity for each quadrat (see also Christman and Zagmajster 2012).

This fallacy appears in cases where existing data for karst areas are used to estimate species richness for unsampled karst areas. This is apparently part of the procedure used by Guzik et al (2010) to estimate species richness of unsampled calcrete aquifers. One consequence and indication of the Fallacy of Isotropy is that it results in very large estimates of species numbers and no confidence intervals can be placed on this estimate. Thus, Guzik et al (2010) estimate 4140 species, more than ten times the number of described species. Perhaps they are correct but it is of little comparative value because there are no estimates for other areas done in a similar manner.

The fourth fallacy is the Fallacy of Scale Invariance. Gibert and Deharveng (2002) suggested and Malard et al (2009) later confirmed that within a region, that local single-cave species richness ( $\alpha$-diversity) is a small fraction of the total species richness. While comparisons between countries are frequent, if only in a rather casual sense, rarely if ever are differences in area (or more appropriately area of karst) taken into account. Statements about numbers of species in a state or country (e.g., Elliott 2007; Trajano and Bichuette 2009) are of no comparative use unless information on the relationship between species numbers and area is included.

Differences in area could be safely ignored if average species richness for a single cave were a good predictor of regional species richness. Then $\alpha$-diversity could be used as a surrogate for regional diversity. A way to test this is to see if species accumulation curves (or their analytical equivalent, Mao-Tau curves) for $1,2,3, \ldots$ randomly chosen caves cross. Dole-Olivier et al (2009b) show that the Mau-Tau curves for the stygofuana of the intensively studied regions that were part of the European Union PASCALIS (Protocols for the Assessment and Conservation of Aquatic Life in the Subsurface) project (Fig. 1) do indeed cross. Culver et al (2006) also found crossing of curves, although in this case crossing occurred near the origin, i.e., at small numbers of caves.

The fifth fallacy is the Fallacy of Misuse of Expert Opinion. The recent estimate of Guzik et al (2010) falls into this trap, at least in part. They provide estimates, by taxonomic group by taxonomic experts, but without estimates for other areas they compare their study region to. The previous discussion of the fate of undescribed species from West Virginia (Tables 1 and 2) is a detailed description of the difficulties with expert opinion. Unless multiple experts are used (as is done for example in developing indices of biological integrity [Barbour et al 1999]), or the same expert evaluates multiple regions, it is difficult if not impossible to evaluate different expert opinion by the same set of criteria. For example, what is the frequency of undescribed cryptic species (see Trontelj et al 2009)? Subterranean biology is fortunate that there are a number 


\section{a}

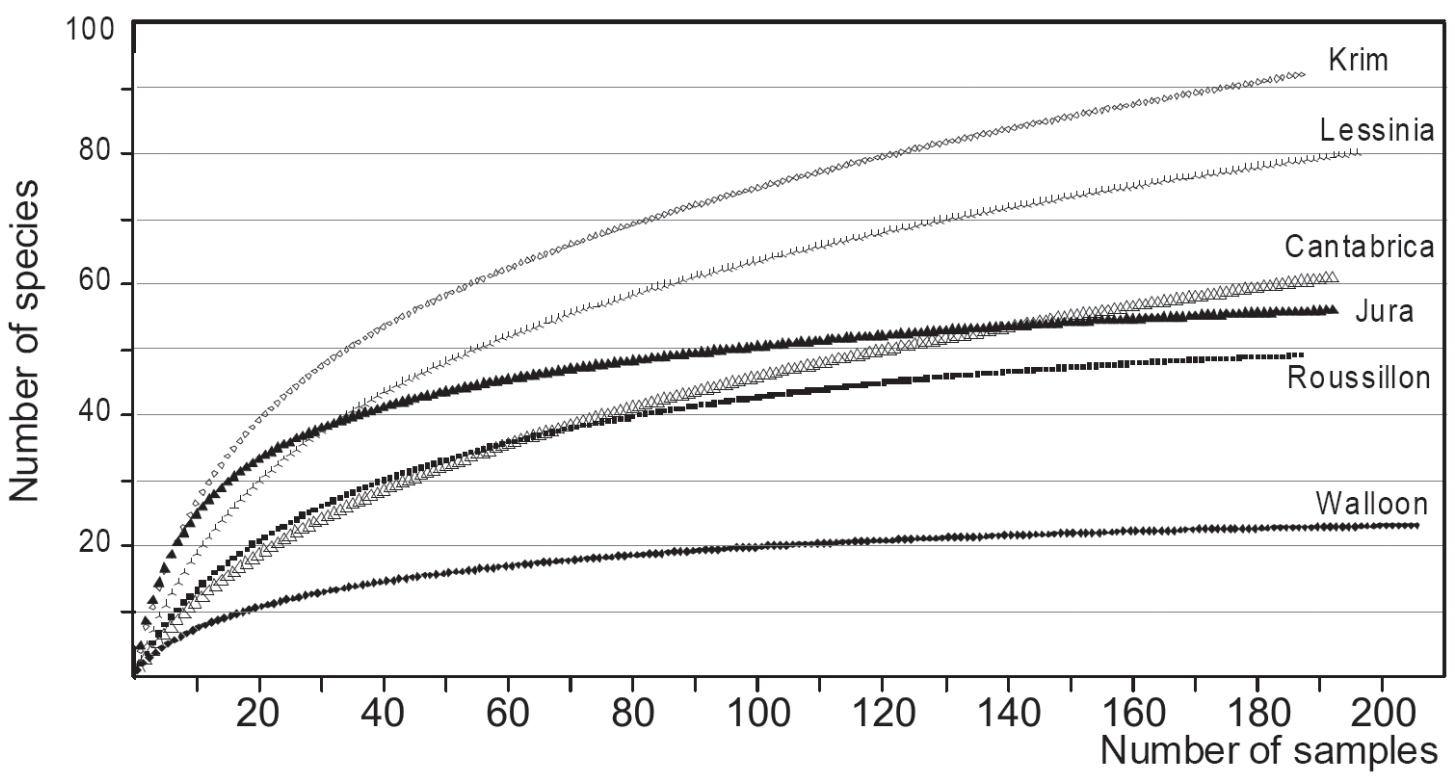

b
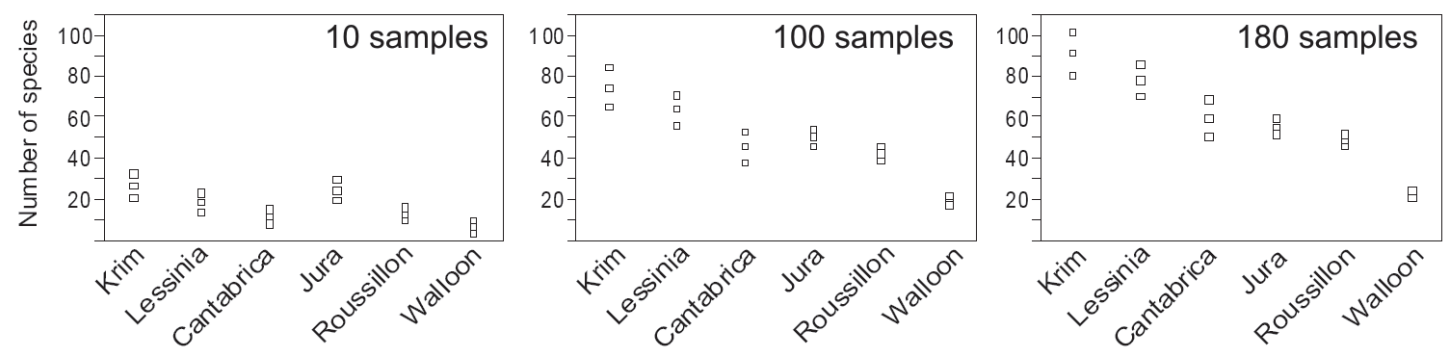

Fig. 1 - Species accumulation curves for stygobionts in the six European PASCALIS regions (top) and 95 percent confidence for the observed number of species (Mao-Tau estimate of Colwell et al [2004]) for three different sampling efforts: 10, 100, and 180 samples (bottom). Sampling regions are Krim Mountain (Slovenia), Lessinian Mountains (Italy), Cantabrica (Spain), Jura Mountains (France), Roussillon (France), and Walloon (Belgium). From Dole-Olivier et al (2009b).

of experts on both particular taxonomic groups and on regional faunas, and as authors we include ourselves in that group. Nevertheless, while expert knowledge is important, there are better and more repeatable ways to estimate species richness, especially those developed to estimate missing species, and widely available in the free software EstimateS (Colwell 2009). If nothing else, they are less prone to subjective interpretations and more easily comparable among regions.

\section{SOME RECOMMENDATIONS}

Subterranean biodiversity is often a matter of national and regional pride, and this increases public awareness and often enhances conservation efforts. Poorly documented diversity claims, involving the fallacies we outline above, do make it difficult to put together an accurate picture of global subterranean biodiversity. There has been an explosion of quantitative information about pat- terns of subterranean species richness, especially at the regional and continental level, yet the broadest scale yet attempted is a European-North American comparison, for terrestrial (Culver et al 2006) and to a very limited extent for aquatic species (Gibert et al 2009). The elucidation of the overall global pattern of subterranean biodiversity is perhaps within reach, but only if data are both comparable and extensive. The following list of recommendations is designed to be the first step in a continuing discussion of how subterranean biodiversity assessment can best be accomplished.

Databases on subterranean biodiversity should, to the greatest possible extent, be based on georeferenced localities. The availability of online georeferenced maps, such as Google Earth ${ }^{\odot}$ make georeferencing of sites much easier than in the past. This enables not only more exact mapping, but also spatial modeling, including spatial autocorrelation (Zagmajster et al 2008), conditional autoregression (Christman and Culver 2001), and kriging (Christman and Zagmajster 2012) . 


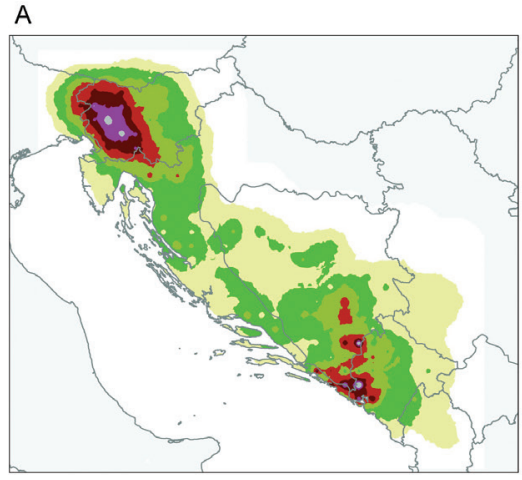

Number of species

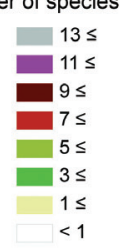

B

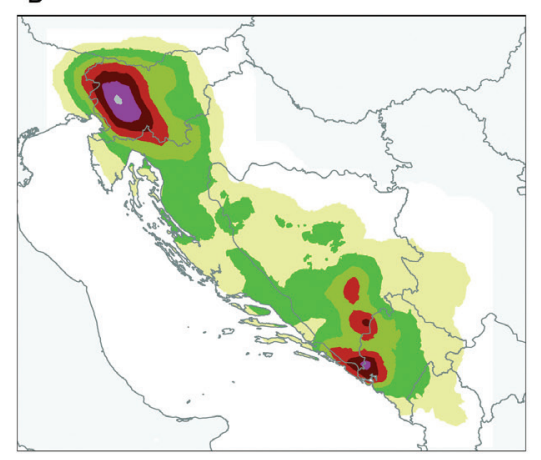

0
100

C

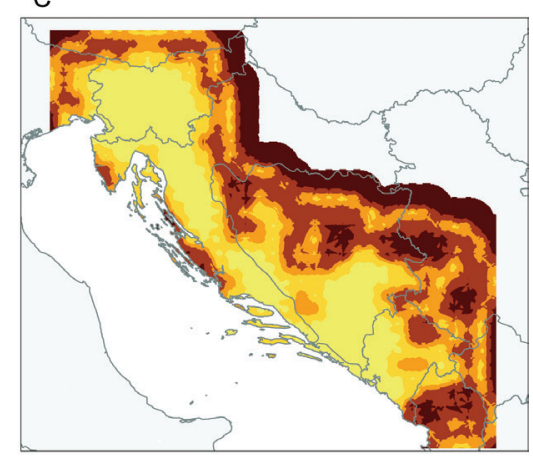

Prediction standard error

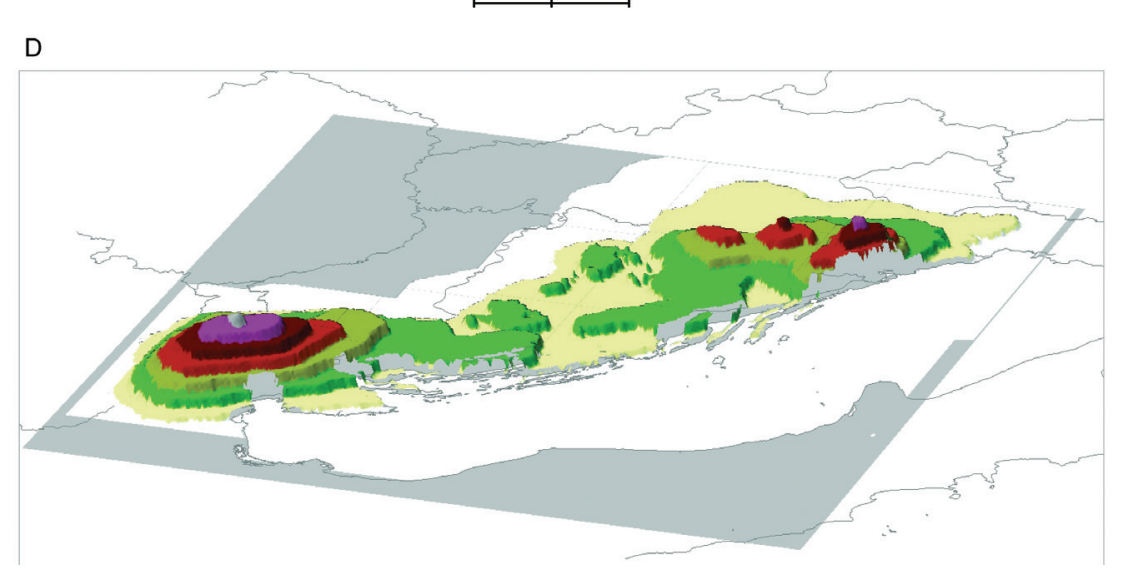

$3,473-4,890$

$3,249-3,328$ $3,249-3,328$
$3,147-3,249$ $3,147-3,249$
$3,093-3,147$

Fig. 2 - Different graphical representations of the same data, number of obligate subterranean beetles (from families Cholevidae and Carabidae) per 20X20 km quadrats in northwestern Balkans. (A) Filled contours based on inverse distance weighting; (B) filled contours based on ordinary kriging; (C) prediction standard error map of ordinary kriging; (D) a three-dimensional presentation of the ordinary kriging predictions. Scale refers to (A), (B) and (C). The first legend refers to (A), (B), and (D), and the second legend to (C). From Christman and Zagmajster (2012).

To the greatest extent possible, the actual data, especially species lists should be made available. This is especially important for large-scale and global comparisons. Without such lists it is impossible to evaluate the claim, especially when exceptional levels of diversity are present. For example, Ozimec and Lučić (2009) report 101 stygobionts and troglobionts in the biodiverse Vjetrenica in Bosnia \& Hercegovina, making it the most biologically diverse cave in the world. Yet they published no species list so this claim cannot be evaluated ${ }^{2}$.

For comparative purposes, it is necessary to treat stygobionts and troglobionts separately from non-obligate species. At the same time, they are necessary because differences of opinion exist as to which species are stygobionts and troglobionts. Whatever the criteria used, it should be stated. For example, Fong et al (2007) use a strictly distributional criterion $(>90$ percent of the records are subterranean) to define stygobionts and troglobionts in West Virginia, but others (Graening et al 2012)

\footnotetext{
${ }^{2}$ Sket (2003) does provide a list of 68 stygobionts and troglobionts from the cave.
}

use morphological criteria as well. Differences in criteria can make for differences in what species are included.

Estimates of unknown species should be made using standard estimation techniques, such as Chao 2 and bootstrap estimators (e.g. Deharveng et al 2009), which also makes it possible to assign confidence intervals to the esimates. Zagmajster et al (2010) also provide methods for minimizing the effect of different sampling intensities.

For assessment of diversity in a region, there is no substitute for large amounts of inventory data and and a thorough geospatial analysis. Christman and Zagmajster (2012) provide a guide to using these techniques. At a minimum, areas need to be gridded, appropriate grid size needs to be determined (Zagmajster et al 2008), and maps need to be made. See Figure 2 for an example of what can be done with good data and good geospatial modeling.

\section{SUMMING UP}

While it has been the purpose of this essay to point out some pitfalls in subterranean biodiversity analysis, this 
does not mean that we believe that such analyses are either unimportant or premature. Because of the ubiquitous Linnean shortfall and the Wallacean shortfall in subterranean faunas, there has been a tendency of speleobiologists to avoid any quantitative summary of regional faunas, claiming it is premature. The problem is that both the Linnean shortfall and the Wallacean shortfall are likely to continue indefinitely. Consider the Wallacean shortfall. Even in relatively well studied regions like West Virginia and Slovenia, less than 20 percent of known caves have been investigated biologically, even in a cursory way. Since new caves are discovered every year even in well studied regions, a complete inventory is highly unlikely. The well known shortage of taxonomists suggests that the taxonomic backlog is permanent. For the West Virginia cave fauna, the taxonomic backlog is apparent (Tables 1 and 2).

Rather than focus on what we don't know, we choose to emphasize what is known. There is not accurate count of the number of described species, but it is surprisingly large. Gibert and Culver (2009) summarize the known stygobiotic species richness as follows:

\author{
Europe-2000 \\ Asia-561 \\ Africa-335 \\ North America-500 \\ South America-100 \\ Oceania-220
}

for a total of 3716. Although not tabulated, the number of described troglobionts is several times that. Even though the number of undescribed species is much greater, the patterns of described species, especially when augmented with estimates of missing species can provide valuable insights into subterranean biodiversity patterns (Zagmajster et al 2010).

There is also reason for optimism that even highly incomplete data can provide robust information about the location of high diversity areas. Culver et al (2004) showed that the location of subterranean biodiversity hotspots in Slovenia was basically unchanged from the 1950's, when they compared current information with that available in 1950. During decades of research, absolute numbers of species increased substantially, but relative numerical relationships between areas remained largely unaffected by additional sampling effort. Perhaps the time is right for a large-scale global assessment of subterranean biodiversity based on a standard methodology.

\section{REFERENCES}

Barbour, M.T., J. Gerritwsen, B.D. Snyder, J.B. Stribling. 1999. Rapid bioassessment protocols for use in streams and wadeable rivers: periphyton, benthic macroinvertebrates and fish, second edition. Environmental Protection Agency Document No. 841-B-99-002.
Botosaneanu, L. [ed.] 1986. Stygofauna mundi. Leiden: E.J. Brill.

Christiansen, K.A. 1962. Proposition pour la classification des animaux cavernicoles. Spelenca 2: 75-78.

Christman, M.C., D.C. Culver. 2001. The relationship between cave biodiversity and available habitat. Journal of Biogeography 28: 367-380.

Christman, M.C., M. Zagmajster. 2012. Mapping subterranean biodiversity. Pp. 474-481 in W.B. White, D.C. Culver, eds. Encyclopedia of caves. Second edition. Amsterdam: Elsevier.

Cobolli Sbordoni M., M. Mattoccia, G. La Rosa, E. De Matthaeis, V. Sbordoni. 1990. Secondary sympatric occurrence of sibling species of subterranean shrimps in the Karst. International Journal of Speleology 19: 9-27.

Colwell, R.K. 2009. EstimateS: Statistical estimation of species richness and shared species from samples. Version 8.2. User's Guide and application published at http://purl.oclc.org/estimates.

Colwell, R.K., C.X. Mao, J. Chang. 2004. Interpolating, extrapolating, and comparing incidence-based species accumulation curves. Ecology 85: 2717-2727.

Culver, D.C., M.C. Christman, W.R. Elliott, H.H. Hobbs III, J.R. Reddell. 2003. The North merican obligate cave fauna: regional patterns. Biodiversity and Conservation 12: 441-468.

Culver, D.C., M.C. Christman, B. Sket, P. Trontelj. 2004. Sampling adequacy in an extreme environment: species richness patterns in Slovenian caves. Biodiversity and Conservation 13: 1209-1229.

Culver, D.C., L. Deharveng, A. Bedos, J.J. Lewis, M. Madden, J.R. Reddell, B. Sket, P. Trontelj, D. White. 2006. The mid-latitude biodiversity ridge in terrestrial cave fauna. Ecography 29: 120-128.

Culver, D.C., J.R. Holsinger. 1992. How many species of troglobites are there? National Speleological Society, Bulletin 54:79-80.

Culver, D.C., T. Pipan. 2009. The biology of caves and other subterranean habitats. Oxford: Oxford University Press.

Culver, D.C., T. Pipan. 2012. Subterranean ecosystems. In S.A. Levin, ed. Encyclopedia of biodiversity, second edition. Amsterdam: Elsevier.

Culver, D.C., B. Sket. 2000. Hotspots of subterranean biodiversity in caves and wells. Journal of Cave and Karst Studies 62: 11-17.

Deharveng, L., F. Stoch, J. Gibert, A. Bedos, A., D. Galassi, M. Zagmajster, A. Brancelj, A.I. Camacho, F. Fiers, P. Martin, N. Giani, G. Magniez, P. Marmonier. 2009. Groundwater biodiversity in Europe. Freshwater Biology 54: 709-726.

Dole-Olivier, M.J., F. Malard, P. Martin, T. Levébure, J. Gibert. 2009a. Relationships between environmental gradients and groundwater biodiversity at a regional scale. Freshwater Biology 54: 797-813

Dole-Olivier, M.-J., F. Castellarini, N. Coineau, N., D.M.P. Galassi, P. Martin, N. Mori, A. Valdecasas, 
J. Gibert. 2009b. Towards an optimal sampling strategy to assess groundwater biodiversity: comparison across six regions of Europe. Freshwater Biology 54:777-796.

Eberhard, S.M., S.A. Halse, M.R. Williams, M.D. Scanlon, J.S. Cocking, H.J. Barron. 2009. Exploring the relationship between sampling efficiency and short range endemism for groundwater fauna in the Pilbara region, Western Australia. Freshwater Biology 54: 885-901.

Elliott, W.R. 2007. Zoogeography and biodiversity of Missouri caves and karst. Journal of Cave and Karst Studies 69: 135-172.

Fong, D.W,, D.C. Culver, H.H. Hobbs III, T. Pipan. 2007. The Invertebrate cave fauna of West Virginia, second edition. Barrackville: Bulletin of the West Virginia Speleological Survey, No. 16.

Gibert, J., D.C. Culver 2009. Assessing and conserving groundwater biodiversity: an introduction. Freshwater Biology 54: 639-648.

Gibert, J., D.C. Culver, M.-J. Dole-Oliver, F. Malard, M.C. Christman, L. Deharveng. 2009. Assessing and conserving groundwater biodiversity: synthesis and perspectives. Freshwater Biology 54: 930-941.

Gibert, J., L. Deharveng. 2002. Subterranean ecosystems: a truncated functional biodiversity. Bioscience 52: 473-481.

Graening, G.O., D.B. Fenolio, M.E. Slay. 2012. Cave life of Oklahoma and Arkansas. Norman: University of Oklahoma Press.

Guzik, M.T., A.D. Austin, S.J.B. Cooper, M.S. Harvey, W.F. Humphreys, T. Bradford, S.M. Eberhard, R.A. King, R. Leys, K.A. Muirhead, M. Tomlinson. 2010. Is the Australian subterranean fauna uniquely diverse? Invertebrate Systematics 24: 407-418.

Holsinger, J.R., Baroody, R.A., D.C. Culver. 1976. The invertebrate cave fauna of West Virginia. Barrackville: Bulletin of the West Virginia Speleological Survey, No. 7.

Lefébure, T., C.J. Douady, M. Gouy, J. Gibert. 2006. Relationship between morphology, taxonomy, and molecular diversity with Crustacea: proposal of a molecular threshold to help species definition. Molecular Phylogeny and Evolution 40: 435-447.

Malard, F., C. Boutin, A.I. Camacho, D. Ferreira, G. Michel, B. Sket, F. Stoch. 2009. Diversity patterns of stygobiotic crustaceans across multiple spatial scales in western Europe. Freshwater Biology 54: 756-776.

Martin, P., C. De Broyer, F. Fiers, G. Michel, R. Sablon, K. Wouters. 2009. Biodiversity of Belgain groundwaters and characterization of their stygobiotic fauna from a historical and ecological perspective. Freshwater Biology 54: 814-829.

Myers, N. 1988. Threatened biotas: "Hot spots" in tropical forests. The Environmentalist 8: 187-208.

Ozimec, R., I. Lučić. 2009. The Vjetrenica cave (Bosnia $\&$ Herzegovina) - one of the world's most prominent biodiversity hotspots for cave-dwelling fauna. Subterranean Biology 7: 17-24.

Peck, S. B. 1998. A summary of diversity and distribution of the obligate cave-inhabiting faunas of the United States and Canada. Journal of Cave and Karst Studies 60: 18-26.

Pipan, T. 2005. Epikarst - a promising habitat. Ljubljana: ZRC SAZU Založba.

Pipan, T., D.C. Culver. 2007a. Regional species richness in an obligate subterranean dwelling fauna - epikarst copepods. Journal of Biogeography 34:854-861.

Pipan, T., D.C. Culver. 2007b. Copepod distribution as an indicator of epikarst system connectivity. Hydrogeology Journal 15:817-822.

Shear, W.A. 2008. Cave millipeds of the United States. VII. New species and records of the genus Pseudotremia Cope. I. Species from West Virginia, USA (Diplopoda, Chordeumatida, Cleidogonidae). Zootaxa 1764: 53-65.

Shear, W. A. 2010. Hesperonemastoma smilax, n.sp., a remarkable new Harvestman from a cave in West Virginia, with comments on other reported cave-dwelling Hesperonemastoma species (Opiliones, Ischyropsalidoidea, Sabaconidae). Journal of Cave and Karst Studies 72: 105-111.

Sket, B. 1999. High biodiversity in hypogean waters and its endangerment- the situation in Slovenia, the Dinaric Karst, and Europe. Crustaceana 72: 767-780.

Sket, B. 2003. Životinjski svijet Vjetrenice. Pp. 147-248 in I. Lučić, ed. Vjetrenica: pogled u dušu zemlje. Croatia: Zagreb.

Soto-Adames, F.N. 2010. Two new species and descriptive notes for five Pseudosinella species (Hexapoda: Collembola: Entomobryidae) from West Virginian (USA) caves. Zootaxa 2331: 1-34.

Trajano, E., M.E.Bichuette. 2009. Diversity of Brazilian subterranean invertebrates, with a list of troglomorphic taxa. Subterranean Biology 7:1-16.

Trontelj, P., C.J. Douady, C. Fišer, J. Gibert, Š. Gorički, T. Lefébure, B. Sket, and V. Zakšek. 2009. A molecular test for cryptic diversity in ground water: how large are the ranges of macro-stygobionts? Freshwater Biology 54: 727-744.

Zagmajster, M., D.C. Culver, and B. Sket. 2008. Species richness patterns of obligate subterranean beetles in a global biodiversity hotspot - effect of scale and sampling intensity. Diversity and Distributions 14: 95-105.

Zagmajster, M., D.C. Culver, M.C. Christman, and B. Sket. 2010. Evaluating the sampling bias in pattern of subterranean species richness - combining approaches. Biodiversity and Conservation 19:3035-3048.

Zakšek V, B. Sket, S. Gottstein, D. Franjević, P. Trontelj. 2009. The limits of cryptic diversity in groundwater: phylogeography of the cave shrimp Troglocaris anophthalmus (Crustacea: Decapoda: Atyidae). Molecular Ecology 18: 931-946. 